\title{
UTILIZING THE SYNERGY OF AIRBORNE BACKSCATTER LIDAR AND IN-SITU MEASUREMENTS FOR EVALUATING CALIPSO
}

\author{
Alexandra Tsekeri ${ }^{1 *}$, Vassilis Amiridis ${ }^{1}$, Franco Marenco ${ }^{2}$, Eleni Marinou ${ }^{1}$, Phil Rosenberg ${ }^{2}$, \\ Stavros Solomos ${ }^{1}$, Jamie Trembath ${ }^{2}$, James Allan ${ }^{3}$, Asan Bacak ${ }^{3}$ and Athanasios Nenes ${ }^{4}$ \\ ${ }^{1}$ IAASARS, National Observatory of Athens, Athens, Greece, *Email: atsekeri@noa.gr \\ ${ }^{2}$ Observational Based Research, Met Office, Exeter, UK \\ ${ }^{3}$ School of Earth, Atmospheric and Environmental Sciences, University of Manchester, Manchester, UK \\ ${ }^{4}$ School of Earth and Atmospheric Sciences and Chemical and Biomolecular Engineering, Georgia \\ Institute of Technology, Atlanta, Georgia, USA
}

\begin{abstract}
Airborne campaigns dedicated to satellite validation are crucial for the effective global aerosol monitoring. CALIPSO is currently the only active remote sensing satellite mission, acquiring the vertical profiles of the aerosol backscatter and extinction coefficients. Here we present a method for CALIPSO evaluation from combining lidar and in-situ airborne measurements. The limitations of the method have to do mainly with the in-situ instrumentation capabilities and the hydration modelling. We also discuss the future implementation of our method in the ICE-D campaign (Cape Verde, August 2015).
\end{abstract}

\section{INTRODUCTION}

Characterizing effectively the vertical distribution of the aerosol optical and microphysical properties is very important, considering their effects on climate. The space-borne lidar CALIOP on-board the CALIPSO satellite provides profiles of the aerosol backscatter and extinction coefficients, along with information on layer-stratified types of aerosol. The validation of these products is an ongoing effort employing ground-based and airborne lidars (e.g. [1]). In Figure 1 we show the validation of the CALIPSO extinction product during the South American Biomass Burning Analysis (SAMBBA) campaign [2].

In the framework of ACEMED campaign (Evaluation of CALIPSO's aerosol classification scheme over Eastern Mediterranean) we proposed a new methodology for an effective characterization of the particle vertical distribution from airborne campaigns dedicated to active remote sensing satellite validation. Our retrieval utilizes airborne backscatter lidar and in- situ measurements. The in-situ data refer to dried particle samples, thus, in order to obtain the ambient particle properties we model their hygroscopic growth with ISORROPIA II model [3].

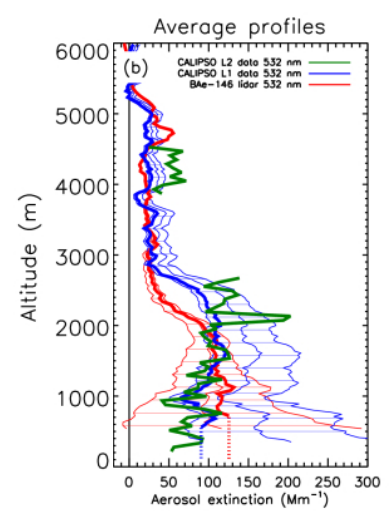

Figure 1: CALIPSO aerosol extinction coefficient at $532 \mathrm{~nm}$ (green), compared to the airborne lidar extinction coefficient at $532 \mathrm{~nm}$ (red) and the extinction coefficient retrieved from the Level 1 CALIPSO data (blue), as described in [2], during the SAMBBA campaign.(Source: [2])

\section{DATA and METHODOLOGY}

On 8/9/2011 the Facility for Airborne Atmospheric Measurements (FAAM) BAe-146 research aircraft performed nighttime airborne lidar and in-situ aerosol measurements at different height levels during an under-flight of CALIPSO. Central to our approach is the synergy of the acquired remote sensing and in-situ measurements: The elastic backscatter lidar signals provide information about the ambient particle properties which though is not enough to achieve a complete characterization of the ambient particles. The in-situ measurements on the other hand provide along with optical properties, the size distribution and chemical 
composition of the particles, from which we can derive their refractive index. Unfortunately these measurements refer to particle samples dried onboard. Moreover, they come with uncertainties, especially for the larger particles and for the imaginary part of the refractive index.

In order to calculate the aerosol optical and microphysical properties at different flight altitudes, we used the measured dry size distributions and refractive indices as a first guess in the retrieval and changed them iteratively, so as their scattering properties reproduce both the insitu optical measurements and the lidar backscatter signals (Figure 2). The hygroscopic growth of the particles in ambient conditions was modelled with ISORROPIA II.

\section{Methodology overview}

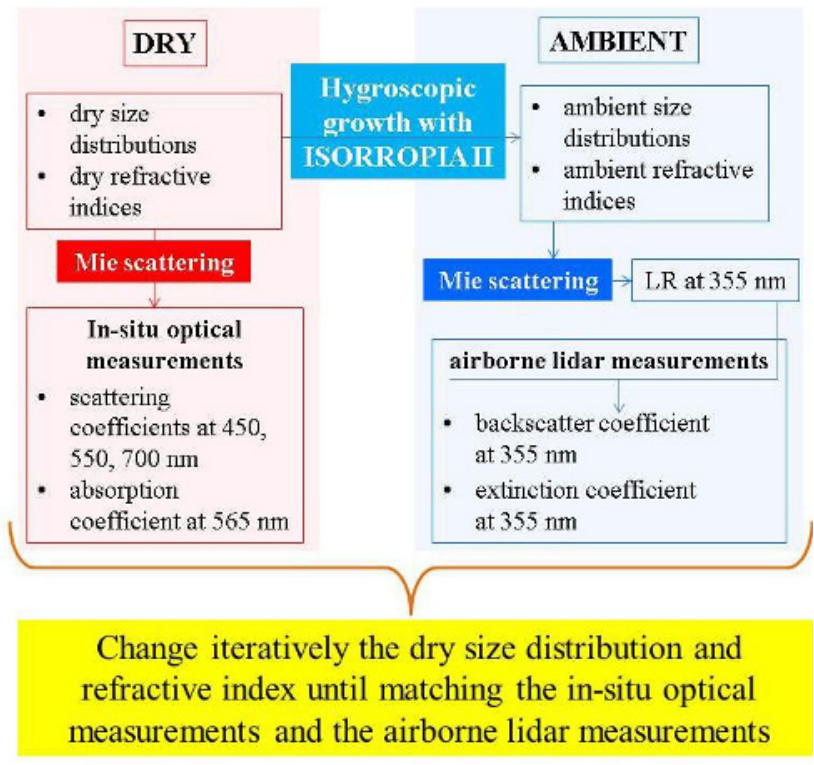

Figure 2: Methodology overview.

\section{Airborne lidar data}

The active remote sensing airborne measurements were performed with the NON-CORE Mini-Lidar Leosphere ALS450 system onboard [4] acquiring backscatter and depolarization profiles at $355 \mathrm{~nm}$.

\section{Airborne in-situ data}

The in-situ instruments onboard the BAe-146 aircraft measured a large suite of the particle microphysical and optical characteristics, as the size distribution, the chemical composition, the scattering and absorption coefficients:

\section{$\underline{\text { Size distribution }}$}

The number size distributions were measured with the Passive Cavity Aerosol Spectrometer Probe (PCASP) and the 1.129 Grimm Technik Skyoptical particle counter (OPC), operating at the $0.1-3$ and $0.25-32 \mu \mathrm{m}$ (nominal) diameter range, respectively. The measurements were calibrated following the methodology in [5]. As can be seen in Figure 3 the fine mode for both datasets is almost identical, but for the coarse mode this is not true, especially for particles with radius $>1$ $\mu \mathrm{m}$. The comparison with the ambient size distributions provided by AERONET measurements before and after the BAe-146 aircraft flight, shows that for the fine mode there is good agreement which though deteriorates for larger particles. This can be also due to the AERONET size distribution cut-off at $15 \mu \mathrm{m}$.

$\underline{\text { Refractive index }}$

The chemical composition provided by the Aerosol Mass Spectrometer (AMS) of FAAM can be used to estimate the particle refractive index, applying a volume mixture law to account for the contributions of the corresponding chemical groups [6]. This approach introduces some uncertainties, especially in the estimation of the imaginary part, thus in our retrieval the AMScalculated refractive indices are used only as a first guess and the actual refractive indices are calculated from the iterative scheme described above, to achieve the best closure between all measurements. We considered different refractive indices for fine and coarse particles.

\section{Scattering and absorption}

The particle dry scattering coefficients at 450, 550 and $700 \mathrm{~nm}$ were measured with the TSI Integrating Nephelometer 3563 and the absorption coefficient at $567 \mathrm{~nm}$ was measured with the Radiance Research Particle Soot Absorption Photometer (PSAP). Both instruments are connected to modified Rosemount inlets, suffering from inlet enhancement/losses as well as losses along the pipelines and they do not measure the scattering properties over the whole particle size range. For this reason, in our scattering calculations we consider a sampling cut-off for particles with radius $>3 \mu \mathrm{m}$. 


\section{Hygroscopic growth}

ISORROPIA II models the thermodynamic equilibrium of aerosols in different atmospheric states [3]. The software takes as input the dried sample properties, i.e., the particle size distribution and chemical composition, along with the temperature, pressure and relative humidity (RH) of the sample, and the temperature, pressure and $\mathrm{RH}$ of the ambient atmosphere and calculates the hygroscopic growth of the fine and coarse modes. In our analysis a modified version of ISORROPIA II is utilized, taking in account the hygroscopic growth of the organic material as well.

\section{RESULTS}

Figure 4 shows the dry and the hygroscopically grown ambient size distributions at $2.7 \mathrm{~km}$ (the $\mathrm{RH}$ is $74 \%$ at this height) for the ACEMED flight of September $9^{\text {th }}$, 2011, above Thessaloniki.

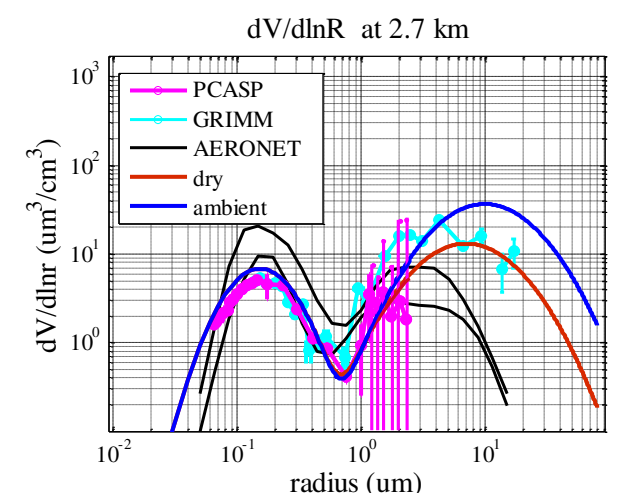

Figure 3: The retrieved size distributions for dried (red) and ambient particles (blue), at $2.7 \mathrm{~km}$. The measured size distributions are from PCASP (pink) and Grimm (cyan). The ambient size distributions from AERONET before and after the flight are shown in black.

The size distributions are retrieved from our iterative scheme, so as together with the retrieved refractive indices to reproduce the lidar and in-situ measured optical properties. The fine mode is set equal to the measurements and the coarse mode is varied, due to the uncertainties in its definition. The refractive indices for fine and coarse modes are varied too.

Figure 4 shows the measured scattering coefficients versus the calculated ones from the retrieved size distributions and refractive indices. Generally, we see that our calculations reproduce the in-situ measurements well (the agreement for the absorption coefficient at $567 \mathrm{~nm}$ is similar).

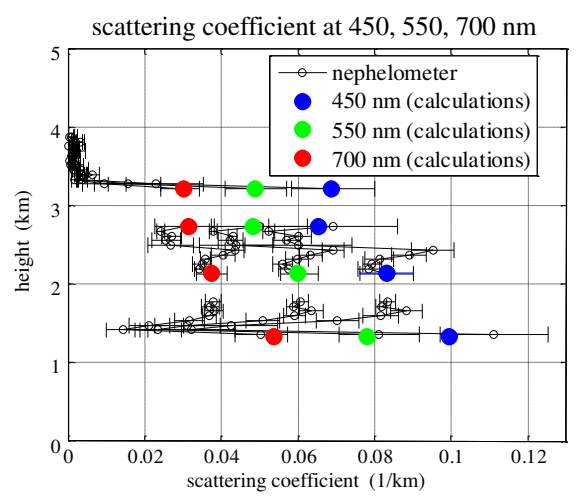

Figure 4: The calculated scattering coefficients at 450 (blue), 550 (green) and $700 \mathrm{~nm}$ (red), at different flight heights. The measurements from the nephelometer are shown in black.

Figure 5 shows the measured versus the calculated backscatter coefficient at $355 \mathrm{~nm}$. It seems that the calculations fit the measurements well, and the same is true for the extinction coefficient at 355 nm (not shown).

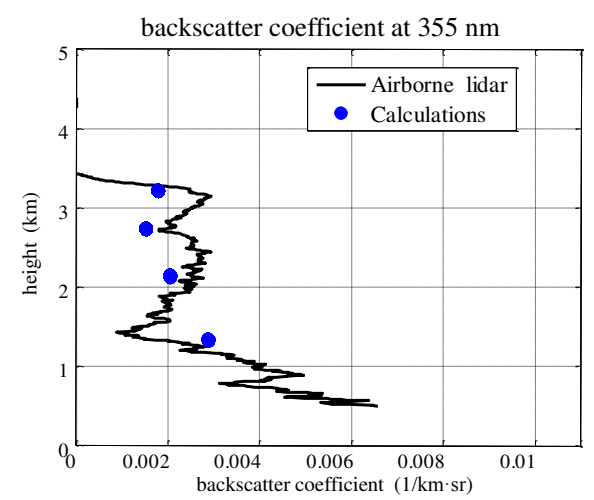

Figure 5: The backscatter coefficient at $355 \mathrm{~nm}$ measured by the airborne lidar (black) and calculated from the retrieved aerosol microphysichal properties (blue).

Small discrepancies between the measurements and the calculations are due to the uncertainty in the coarse mode and possibly in uncertainties in the hygroscopic modelling of the ambient particles. Moreover they can be due to changes in the atmospheric properties, since the measurements are not simultaneous, with the lidar measurements to be an average of the whole flight and the in-situ measurements to refer at differentaltitude portions of the flight. 
The retrieved size distributions and refractive indices are then used to calculate the backscatter and extinction coefficients at $532 \mathrm{~nm}$, and to evaluate the respective CALIPSO product. As shown in Figure 6 our calculations are quite close to the CALIPSO measurements. We need to highlight here that the CALIPSO data were not used in the iterative procedure.
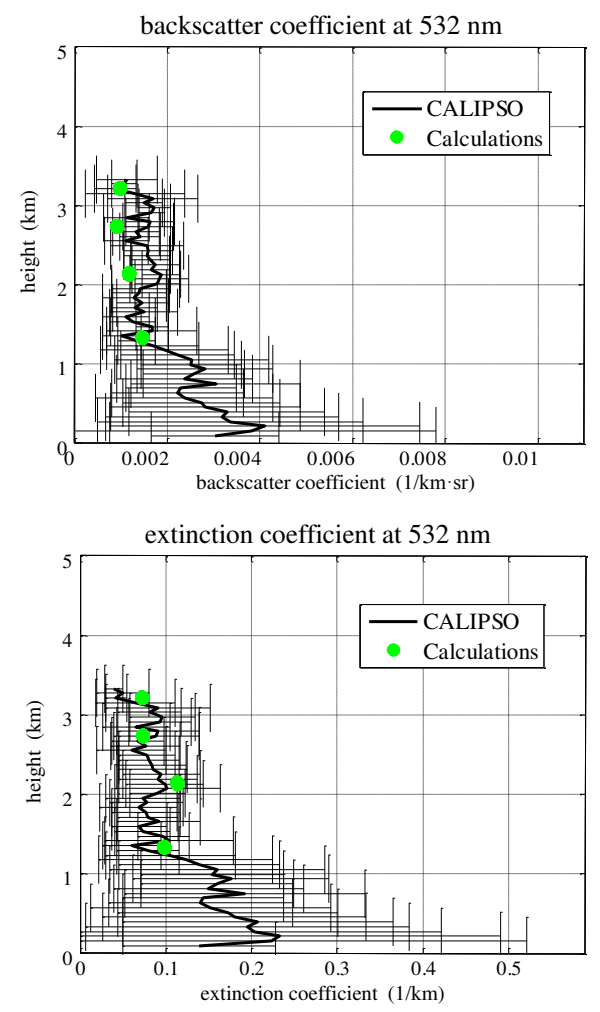

Figure 6: The backscatter (top) and extinction coefficient (bottom) at $532 \mathrm{~nm}$ from CALIPSO (black) and calculated from the retrieved aerosol microphysichal properties (green). The errorbars denote the variability of the CALIPSO products.

\section{CONCLUSIONS and FUTURE WORK}

The iterative closure of airborne active remote sensing with in-situ measurements produced successful results for the characterization of the aerosol at different flight heights for a specific case of ACEMED campaign. This method can be widely used for the validation of active remote sensing satellite products. Our aim is to utilize it in future validation campaigns, as the ICE-D campaign organized in August 2015, focused on dust monitoring.

\section{ACKNOWLEDGEMENT}

The research leading to these results has received funding from the European Community's Seventh Framework Programme (FP7/2007-2013) under grant agreement $\mathrm{n}^{\circ} 227159$ (EUFAR: European Facility for Airborne Research in Environmental and Geo-sciences). Airborne data was obtained using the BAe-146-301 Atmospheric Research Aircraft [ARA] flown by Directflight Ltd and managed by the Facility for Airborne Atmospheric Measurements [FAAM], which is a joint entity of the Natural Environment Research Council [NERC] and the Met Office. The research leading to these results has received funding from the European Union Seventh Framework Programme ACTRIS (FP7/2007-2013) under grant agreement $\mathrm{N}^{\circ} 262254$.

\section{REFERENCES}

[1] Burton, S. P., et al., 2013: Aerosol classification from airborne HSRL and comparisons with the CALIPSO vertical feature mask, Atmos. Meas. Tech., 6, 1397-1412.

[2] Marenco, F., et al., 2014: Airborne verification of CALIPSO products over the Amazon: a case study of daytime observations in a complex atmospheric scene, Atmos. Chem. Phys., 14, 11871-11881.

[3] Fountoukis, C. and Nenes, A., 2007: ISORROPIA II: a computationally efficient thermodynamic equilibrium model for $\mathrm{K}^{+}-\mathrm{Ca}^{2+}-$ $\mathrm{Mg}^{2+}-\mathrm{NH}_{4}{ }^{+}-\mathrm{Na}^{+}-\mathrm{SO}_{4}{ }^{2-}-\mathrm{NO}_{3}{ }^{-}-\mathrm{Cl}^{-}-\mathrm{H}_{2} \mathrm{O}$ aerosols, Atmos. Chem. Phys., 7, 4639-4659.

[4] Marenco, F., et al., 2011: Airborne Lidar Observations of the 2010 Eyjafjallajökull Volcanic Ash Plume, J. Geophys. Res., 116, D00U05, doi:10.1029/2011JD016396.

[5] Rosenberg, P. D., et al., 2012: Particle sizing calibration with refractive index correction for light scattering optical particle counters and impacts upon PCASP and CDP data collected during the Fennec campaign, Atmos. Meas. Tech., 5, 1147-1163.

[6] Highwood, E. J., et al., 2012: Aerosol scattering and absorption during the EUCAARILONGREX flights of the Facility for Airborne Atmospheric Measurements (FAAM) BAe-146: can measurements and models agree?, Atmos. Chem. Phys., 12, 7251-7267. 